Accepted refereed manuscript of:

Skountridaki K (2017) Barriers to Business Relations between Medical Tourism Facilitators and Medical Professionals, Tourism Management, 59, pp. 254-266.

DOI: $\underline{10.1016 / j . t o u r m a n .2016 .07 .008}$

(C) 2016, Elsevier. Licensed under the Creative Commons AttributionNonCommercial-NoDerivatives 4.0 International

http://creativecommons.org/licenses/by-nc-nd/4.0/ 


\title{
Barriers to Business Relations between Medical Tourism Facilitators and Medical Professionals engaged in Transnational Healthcare
}

\begin{abstract}
This paper examines facets of the developing business relations between two important actors in the supply-chain of transnational healthcare: medical tourism facilitators and medical doctors (MDs) practicing privately and internationalising their services. The empirical focus is Greece, an emerging destination for medical care. Drawing on the sociology of the professions as an analytical framework, rich qualitative data reveals a conflictual aspect in the relation between the two actors, and informs the literature on transnational healthcare of barriers to market development. Particularly, MDs practicing privately often resist what is perceived to be medical tourism facilitators' pressures to control the 'rules of the game' in the submarket which inhibits their collaboration. The paper contributes, thus, to the sociology of the professions by bringing to light a new challenge for MDs engaged in the transnational business arena, represented here by the facilitators; and encourages tourism practitioners to consider MDs’ self-understanding, attitudes, and expectations.
\end{abstract}

Keywords: Medical Tourism Facilitators; Medical Professionals; Transnational Healthcare; Medical Dominance; Medical Travel/Tourism

\section{INTRODUCTION}

Transnational healthcare refers to the 'transnational pursuit' (demand) and 'transnational provision' (supply) of medical care (Bell et al., 2015: 285). The first, either 'long-distance' or 'every day' and 'intra-regional', is a practice within the transnational healthcare sector (Bell et al., 2015); according to the World Trade Organisation nomenclature a mode of international trade in health services. Known also as medical tourism it refers to the travel of a person to a foreign country with the aim of receiving medical care; with an emphasis on 'clinical, surgical, and hospital provision' (Carrera and Lunt, 2010). On the other hand, the transnational provision of medical care refers to the 'supply chain' of care, which includes medical care providers, travel agencies, accommodation, and 
transportation services providers (Lee and Fernando, 2015). There is a growing body of literature examining aspects of this developing market (Chuang et al., 2014), and yet much remains to be explored or clarified. There are definitional issues around the term and scope of 'medical tourism' (Connell, 2013; Bolton and Skountridaki, 2017); numeric data are inaccurate or exaggerated (Lunt $e t$ al., 2014); and while patients and national destinations have attracted much scholarly attention (Ormond et al., 2015), less is known about other key stakeholders such as informal care providers (Crooks and Snyder, 2015), the role of intermediaries (Connell, 2013), or the experiences of health professionals (Skountridaki, 2015). Similarly, there is a gap in our knowledge about the dynamics of the sector; how the transnational healthcare sector evolves and grows, including the interactions among key actors, and (contextual) factors or initiatives that promote or dissuade industry developments (Ormond et al., 2015). This paper seeks to address this gap and contribute towards a deeper understanding of industry developments. One way to do so is to explore the developing relationships between key actors, especially if market creation is understood as the result of initiatives and interactions undertaken by various stakeholders. These interactions may involve competition or cooperation; often a combination of the two. As such, aim of the paper is to provide empirical evidence on the interactions between two key actors in the supply chain of transnational healthcare (medical doctors working for small medical providers and medical tourism facilitators) and offer a theoretical interpretation of this evidence through a sociological approach, the sociology of the professions.

Overall, academic contributions and media reports offer evidence of several players in health care considering ways in which internationalisation may prove beneficial for their enterprise, including medical professionals, private hospitals, and governments (see for example Chee, 2010; Labonté, 2013b; Ormond, 2015). Except for perceived opportunities, this paper highlights that the above actors may face new challenges. For example, similar to other industries, transnational regulatory frameworks such as the General Agreement on Trade in Services or European Union legislation may limit the policy choices of governments (see for example the analysis on accounting services by Arnold, 2005). Moreover, as patients move to foreign countries domestic providers may face increasing international competition; and governments may contest the healthcare provision 
offered by foreign providers to their citizens (as in the case of the Indonesian authorities, Ormond, 2015). In addition, particular actors increase their importance in the international terrain (e.g. transnational regulatory bodies, accreditation bodies) and new actors appear, i.e. medical tourism facilitators. The very moment these actors fill a void in the new market, they threaten to differentiate traditional power balances and potentially forge new dynamics. The focus here is on two key actors with different background and history; medical doctors (MDs), who try to internationalise their services by attracting foreign clientele to their private practices (and thus enter into the area of international entrepreneurship), and medical tourism facilitators, who serve the role of an intermediary between demand and supply (and thus now enter the health sector and in particular a niche subsector). Empirically the analysis examines the perceptions of the first over the latter with a focus on Greece as a destination country for medical services. It is important to note here the distinction between small practices and large hospitals that together account for the transnational provision of medical care. While not comparable to large hospitals in terms of size, resources, or the range of medical services, small providers advertise, attract, and serve a segment of the international demand (Snyder et al. 2011; Turner 2013). In light of this, this study notes that small providers are typically run by medical doctors, a body of knowledge-workers meticulously studied for over four decades by the Sociology of the Professions. Because of its focus on professionals, not least on medical professionals, this body of literature is deemed useful to shed light on the evolving MDfacilitator relation; particularly from the perspective of MDs. The sociology of the professions (Larson, 1977; Freidson, 1985; Abbott, 1988) highlights that MDs are incumbents within the healthcare sector; while this paper offers an example of how private practitioners interpret the activities of facilitators as challenging medical power. Findings show that numerous MDs in small/medium private practices do not only do business at an international level (Skountridaki, 2015) but that interactions for business purposes are deeply politicised. In particular, medical professionals vie for control over facilitators about who defines the fees and terms of collaboration. Facilitators are often perceived by medical providers engaging in the international market as a countervailing power (Light, 1995) in the new field; in particular, some MDs express dissatisfaction with the relationship or choose to interrupt collaboration with facilitators for reasons which go beyond monetary concerns. 
Friction results, to a certain extent, in delays in the internationalisation process of providers as it limits the number of provider-facilitator agreements. This mistrust functions as an impediment to market development and generates the need for alternative forms of collaboration.

This paper contributes to knowledge by offering fresh insights both to the Sociology of the Professions and the literature on transnational healthcare/medical tourism/travel. The sociology of the professions examines challenges posed to MDs (both from within the profession and the environment) and the related collective or individual response. The empirical evidence presented here informs the literature of a new market-driven challenge for medical professionals engaging in the international business arena. It also highlights how professionals-owners of small private practices in yet another development in the healthcare sector - advancing internationalisation - attempt to offset the leverage of a new actor, facilitators. Facilitators are for many small providers a unique way to reach foreign clientele. Yet, medical professionals experience the leverage of facilitators as perturbing and remain cautious in their collaborations, thus limiting the expansion of facilitators' operations. This ambivalence of medical professionals working in small medical practices, along with its practical implications, also advances our understanding of how transnational healthcare grows. As mentioned above, little is known about the evolving relations of key actors in the supply side which calls for empirical research aiming to shed light on factors, attitudes, and actions that promote or dissuade transnational healthcare. In light of this, issues of trust by small medical providers towards facilitators are observed, and this paper goes deeper to offer a theory-informed insight into why trust is difficult to establish. Professional norms and attitudes play out as a factor dissuading industry developments. How successfully medical professionals will tackle the challenge in the long-term is uncertain, as various factors create a dynamic and complex environment. Facilitators come from the business world, where medical providers as much in Greece as elsewhere function as small/medium enterprises competing for market share. Claims over a social purpose and an ethic of service for professionals in a highly commercialised sector fade, weakening the ideological legitimacy for professionalism (Skountridaki, 2015). Furthermore, the multinational operation of facilitators places them out of the state's jurisdiction where medical professionals have better chances to deploy political resources and influence their relationships. The international business environment, therefore, coincides with a 
relatively attenuated position for private practitioners. The argument of this paper is presented in five sections. The second section discusses the emergence of transnational healthcare and presents the two key actors. It is followed by a presentation of the theory on medical dominance (the Sociology of the Professions) and how this is applied to the Greek context. The fourth section discusses the methodology and the fifth presents the qualitative data. The final section discusses the findings and concludes the paper.

\section{DEVELOPMENTS AND KEY ACTORS IN THE INTERNATIONALISATION OF} HEALTHCARE

Glinos et al. (2010: 1145) suggest that transnational healthcare is a growing sector not well monitored or understood. They aptly comment that it 'goes beyond the conventional territorial logic' and 'it functions according to different incentives, rules and structures'. The authors take a demandside approach and explore why patients go abroad and how their expenses are covered. On the other hand, this paper takes a supply-side approach to explore how relations among key actors evolve. When considering the rules and structures of the sector (the context in which key actors interact), it is important to highlight that transnational provision is, to a great extent, profit driven. Though crossborder collaboration at a state and non-commercial level is apparent, it is most often related to lack of resources in a particular region (e.g. EU, Rosenmöller et al., 2006) or medical know-how (e.g. African countries, Crush et al., 2012). Commercial incentives and practices are, otherwise, pervasive within the sector. Arguably, commercialisation implies the conceptualisation of healthcare as a service and the delivery of cross-border care as a form of international trade; profit maximisation incentives for providers; advancement of corporate structures at the organisational level; and an augmented importance of business practices such as marketing (Labonté, 2013a). Commercialisation is manifested in various ways. For example, often under the auspices of governments, large medical providers in (potential) 'medical tourism destinations' organise marketing campaigns abroad to attract foreign patients (Crooks et al., 2011); entrepreneurs search for investment opportunities globally, while renowned hospitals seize the opportunity to promote their brand as a form of accreditation for hospitals elsewhere that try to internationalise (Chantarakarn et al., 2013; Hopkins et al, 2010). The internet plays a significant role (Lunt et al., 2009) and business fairs emerge as important venues for 
141 business arrangements among providers, insurers, and facilitators who attend hoping to 'make a deal'

142 (Labonté, 2013b). Characteristic is also the exports orientation exhibited by small providers; arguably,

143 the necessitated deployment of entrepreneurial and marketing skills at an international level comprises

144 a novelty for most of these providers. While similar structures and incentives may appear

145 commonplace in some countries (i.e. the US), commercial practices such as marketing and advertising

146 are restricted in other jurisdictions (e.g. Greece, Taiwan, Turkey etc.). The international field, however, is open to a wider range of commercial practices. Providers or facilitators may exploit differences in national regulatory frameworks. For example, Polish dental practices may not be able to advertise in Greece but they can advertise in in-flight magazines in one of the London-Athens connections; and Greek MDs may not be able to add commercial content to a website with the national extension (.gr) but the law cannot refrain them from doing so in websites with foreign extensions (e.g. .com) or on facilitators' websites when based abroad.

New actors also gain importance in the transnational context. These include 'medical tourism' facilitators, international accreditation and regulatory bodies, and stakeholders from the tourism sector. In particular, medical tourism facilitators aggregate and coordinate the demand (patients seeking care abroad) and supply (medical providers) of health services; they are often called to fill the gap of cultural and language differences, and help with transportation and accommodation arrangements of patients, or the preparation of medical records. At the same time, as they fill a void in the market they also increase provider competition, while they often mediate the traditionally intimate patient-provider relationship (Snyder et al., 2011). In addition, accreditation bodies facilitate market developments in a distinct mode in comparison to medical tourism facilitators. They certify that medical providers adhere to internationally recognised quality standards (Woodhead, 2014), and, therefore, mitigate the problem of trust and support market expansion. They substitute an important function usually undertaken by the state, which also illustrates how international structures overcome national ones. Similarly, the importance of transnational regulatory bodies, such as the European Commission within the EU context, increases. Whereas healthcare has been long excused from European integration, EU is now a zone of advanced initiatives (Jarman and Greer, 2009), with 
European laws increasingly intervening in national healthcare systems under the rationale of a common market and the premise that patient mobility comprises a fundamental EU citizen right.

The above examples reveal current micro- and macro dynamics in transnational healthcare initiated by various stakeholders. The remainder of this section focuses on the role and practices of both actors as depicted in the literature and attempts to identify sources of potential conflict before discussing the findings of the empirical study.

\subsection{Medical Tourism Facilitators: a new business sector}

Medical tourism web portals and agencies are synonymous to the internationalisation of healthcare. Their presence in the UK, US, Australia, Canada, and elsewhere, can be traced from the early 2000s (Turner, 2011). They appeared when growing numbers of patients searching for information online and seeking treatment abroad signalled a new opportunity for business (Turner, 2012; Lunt et al., 2011). Soon they became a key actor offering services to both patients and medical providers. Turner (2013) highlights the importance of the internet in facilitators' business and suggests that the internet functions as a 'global marketing platform' where individuals seeking private healthcare discover facilitators and hospitals beyond their country of residence. As significant number of these individuals contact facilitators to obtain information on overseas healthcare a lesser number use their services to arrange treatment abroad (Snyder et al., 2011). Facilitators offer 'case management services' to patients related to the medical component of the trip, including country and provider recommendation, screening of medical history, preparation for hospitalisation, teleconference with surgeons, along with services related to travelling arrangements, such as lodge recommendation, airfare tickets, visa application, and tourism packages. It is notable that patients do not always pay a fee to facilitators; often it is medical providers who compensate them (Spence, 2009), thus highlighting that facilitators offer important services to medical providers, which include, among others, advertising, patient reference, patient preparation for the trip and/or hospitalisation.

There is diversity in the operations and services of facilitators. Facilitators may operate as a web portal administrated either by a private company or a governmental organisation (Lunt et al., 2009). They may provide information on one or multiple medical facilities; focus on one or multiple destinations (Lunt et al., 2009); and be based in patients' destination or origin country (Frederick and 
Gan, 2015). According to research on 173 facilitators across the continents, most 'non Western'

197 facilitators focus on one destination country, whereas the majority of Western facilitators focus on multiple destinations (Frederick and Gan, 2015). Moreover, their representatives may have limited or no physical contact with patients and medical providers. Others may communicate with patients (and medical providers) in a more personalised way; meeting patients several times before they travel abroad and inspect providers' facilities and credentials.

Facilitators may refer patients to providers without involvement in the medical procedures or travel. Dalstrom (2013) refers to this as 'referral service' facilitators to emphasise their role in connecting a medical provider with a patient without arranging travel and/or medical logistical procedures. Facilitators that play a greater role in patient travel and decision-making are the "full service' facilitators and the 'individual service' facilitators (Dalstrom, 2013). The first make medical and travel arrangements and may offer customised packages to patients, while the latter help patients who are already in the destination country/town to choose a practice, understand laws and procedures, and, through translation services, communicate with providers. In the same spirit, Snyder et al. (2011) make a distinction between brokers and facilitators with the first having a limited role towards patients (typically referring patients to medical providers) and the latter having a more active role (in that they offer extensive advice and may even serve as patient advocates). In this paper the focus is on the common denominator of the intermediating services of facilitators (that is the limited role of referring patients to providers) rather than the differences in the configuration of additional services. In light of this, the 'facilitator' is adopted as a generic term. When deemed meaningful for the analysis, full service or referral facilitators are explicitly distinguished, in line with Dalstrom's analysis (2013). Moreover, where mentioned, 'broker' is understood as a synonym to referral service facilitators.

Facilitators' contribution to the development of the transnational market has further ramifications. Hopkins et al. (2010) mention that facilitators promote agreements with insurance companies in an effort to advance developments in the field. The current research also shows that representatives of 222 facilitators approach providers in various countries to sell their services. They offer a ready 
mechanism which providers may easily join (for an annual subscription or payment per reference) augmenting the international supply.

Concerns over facilitators and their practices are widespread in the literature, though criticism mainly focuses on implications for patients (Lunt et al., 2009; Penney et al., 2011). On the one hand, characterised by high rates of business entry and exit, it is perceived as a 'turbulent' sector (Cormany and Baloglu, 2010; Turner, 2012). On the other hand, it is the strong commercial character of facilitators (Lunt et al., 2009; Labonté, 2013b), coupled with lack of regulation, that causes concern (Turner, 2011); particularly as a significant number of facilitators exhibit a tendency to emphasise benefits and downplay risks of treatment overseas (Mason and Wright, 2011). Low cost, high-quality services, and doctors' expertise are usually promoted (Mason and Wright, 2011). Similarly, factors such as convenience, 24/7 services, friendly healthcare personnel, and assignment of a personal assistant in the destination country (Sobo et al., 2011), or even exotic destinations (Crush et al., 2012: 26), are emphasised. In contrast, health risks are downplayed. Just a minority of reviewed sites in the US and Canada includes information on malpractice, complications, post-operative care, and legal liability (Mason and Wright, 2011: 170; Penney et al., 2011). Parallel to this, credibility is often based on patient testimonials (Mason and Wright, 2011) and simple statements (Penney, 2011).

Conceptually, medical travel is often promoted by facilitators' websites both as a fashionable and conventional behaviour re-occurring through centuries (Sobo et al., 2011). US agencies employ the narrative of patient empowerment, presenting the individual as liberated from gate-keepers and/or social pressure to decide about their healthcare (Sobo et al., 2011). Facilitators also try to tackle patients' concerns over individual responsibility (towards populations at the destination country or the opportunity to 'jump' waiting lists) and present price differences as a result of 'neutral' factors (lower cost of living at destination, lower physician fees, and currency differentiations) (Sobo et al., 2011). Lack of regulation over the practice, however, may entail considerable uncertainty for medical providers too. Information asymmetry potentially passes control to agents over prices, the services, and the choice of buyers/sellers. MDs, who lack knowledge over foreign markets, may depend on them in order to internationalise but lack information mechanisms to control their activities. In light of this, MDs' aversion to facilitators' ability to control the market is anticipated. More so when 
considering MDs as a traditionally dominant actor in the healthcare field with most other actors being either subordinates (i.e. other health occupations) or partners (state, pharmaceuticals). With regards to challengers (healthcare purchasers, patient advocates, the state, other professions) the theory of professions offers rich literature on how MDs strive to maintain their position.

\subsection{The Role of MDs in Building the Market}

Medical doctors' role and perspective on the internationalisation of healthcare vary to a great extent. Some MDs tend to highlight their concerns with patient movement, while others have an active role in the expansion of the phenomenon. For example, medical doctors in South Africa have actively pursued international clientele (Crush et al., 2012: 23). Despite restrictions on advertisements, professional websites, facilitators, referrals and networks, thus, have significantly supported the endeavour (Crush et al., 2012). Similarly, the first efforts of the Singaporean state to attract foreigners in the 1980's, lagged behind the initiatives of some MDs (Chee, 2010: 341). In Costa Rica before large investors paid attention to cosmetic surgery 'tourism', plastic surgeons had started accepting clients from the US in collaboration with hotel owners (Ackerman, 2010: 406). Other examples of entrepreneurial initiatives by MDs in the literature include the case of a Portuguese medical doctor who established a clinic with spa facilities in Macao (Lam et al., 2011: 71), MDs who move to Greece aiming at foreign clientele (Skountridaki, 2015), and a South African agency which is owned and run by MDs (Crush et al., 2012: 27). Online research shows a number of similar cases across the continents ${ }^{\mathrm{i}}$. The above cases illustrate examples of medics who, similar to large providers, try to seize the perceived business opportunities of patients seeking healthcare far from home.

Yet, other medical professionals remain sceptical to the practice. Several Costa Rican surgeons voice critique of colleagues leaving the public sector to service foreigners for higher rewards (Ackerman, 2010: 407). In India, Maheshwari et al. (2012), who work as physicians in a cardiac care unit consulting foreign patients, call on governments to take action to meet local needs and interrupt patient outflows. Based on medical, economic, and moral grounds, scepticism is also expressed by medical doctors in 'origin' countries, such as the UK, US, Canada, Australia, and Germany (Birch et al., 2010; Barrowman et al., 2010; Caulfield \& Zarzeczny, 2012; Cheung and Wilson, 2007; Foss, 2012; Jeevan \& Armstrong, 2008; Jones \& McCullough, 2007; McKelvey et al., 2009; Mattoras, 
2005; Miyagi et al., 2011; Pimlott, 2012; Terzi et al., 2008; Wachter, 2006). The most commonly cited reason refers to increased health risks and is often supported by the authors' own experience with patient complications after treatment abroad. For example, Birch et al. (2011) provide evidence on urgent surgeries they performed in their clinic in Canada on patients who had bariatric surgery overseas, while Barrowman et al. (2010) present five cases of patients treated in hospitals in Melbourne, Australia who had suffered complication after dental treatment abroad. Moreover, Jeevan and Armstrong (2008) suggest that in the UK 37\% of 203 certified plastic surgeons who responded to a survey commissioned by the British Association of Plastic, Reconstructive and Aesthetic Surgeons (BAPRAS) in 2007, had seen patients with post-operative complications after surgery overseas. In light of this, collective agency has also been initiated. For example, the Canadian medical community of fertility and andrology aims at restraining patient movement (Inhorn and Patrizio, 2009: 905), while several plastic surgery associations (BAPRAS, ISAPS, ASAPS), though not always categorically opposed to the practice, have moved fast to prepare guidelines for patients (Miyagi et $a l .$, 2011). In some cases, competition is blurred with concerns over health issues. Empirical research suggests that MDs in origin countries maintain a reserved or even 'antagonistic' sentiment towards facilitators or foreign MDs (Snyder et al., 2011). For example there are accounts of patients who travelled abroad without informing their family doctors, anticipating that they would be dismissive of their decision (Johnston et al., 2012). Moreover, Canadian facilitators feel that MDs in Canada sometimes move patients 'front of waiting lists in order to dissuade them from travelling abroad'; often avoid talking to facilitators or overseas MDs 'because that means that they're approving the process'; or may avoid collaboration as 'it's a kind of a professional suicide' (Snyder et al., 2011, p. $532)$.

Further academic research in various regions across the continents is essential for a deeper understanding of medical professionals' stance and the nature of competition emerging within the profession. What becomes clear is that the positioning of medical doctors plays a role in how they perceive and interpret developments in the international market.

\section{MDs AS INCUMBENTS WITHIN HEALTHCARE PROVISION}


307 Sociology of the Professions explains masterfully how and why MDs have come to occupy this place in a number of societies (Johnson, 1972; Larson, 1977; Starr, 1982; Abbott, 1988; Macdonald, 1995; Freidson, 2001). Medical dominance was originally sanctioned by several states with an aspiration to provide universal access to healthcare during the $20^{\text {th }}$ century (Johnson, 1972; Starr, 1982). It refers to the autonomy of MDs over the organisation and content of their work and, simultaneously, to power asymmetries within healthcare provision that advantage medical professionals over other stakeholders. Power asymmetries are typically observed between MDs and patients (manifested in the patriarchal doctor-patient relationship); and between MDs and members of other health occupations working closely together (most notably nursing staff). After state-introduced managerialism or market-driven corporatism, power struggles over who controls the organisation of healthcare are also observed between MDs and administrators/ managers in numerous states (Kirkpatrick et al., 2009). Though the international literature highlights the 'assault' on medical autonomy and dominance following its golden era (identified around the 1960s by Elliott Freidson in liberal economies, 2001), authority and power asymmetries persist to a considerable extent. consumers (the market) or administrators (bureaucracy) - serves as the cornerstone of medical autonomy. This form of power refers to the right of MDs to define disease, diagnose illness, and decide on the type of treatment for patients (Harrison and Ahmad, 2001). Their 'ability' to do so is exclusive and grounded on their unique set of skills, knowledge, and expertise. Medical knowledge is, thus, a key resource for power and autonomy; while its discretionary application, strengthens the ability of professionals to resist routinisation of their daily work (Doolin, 2002: 374; Hamilton, 2008: 102) even under significant external pressures. McLaughlin and Webster (1998) show, for example, how medics drew on particular resources (legal rights over diagnosis, the dis-attachment of professional skills from the hospital as an organisation, and their membership to the profession) to preserve power and control after the introduction of new technology in a micrology lab. In contrast, the scientific personnel in the same lab proved unable to inhibit deskilling and the downgrading of 
their position. As such, medical professionals often maintain the right to define their fees and own conditions of labour (Flynn, 1999: 22).

Albeit increasingly contested, authority over other actors within healthcare provision including patients and nursing staff is another distinctive feature of medical dominance. MDs typically draw on their superior medical knowledge and skills to reinforce existing power asymmetries in their relation with patients and the public. Carvalho and Nunes (2013) observe that this occurs repeatedly in a number of contexts,

'Studies of participatory procedures involving both scientists/experts and lay members of publics have documented how the agendas of scientists and experts tend to set the terms of their engagements and thus reiterate the epistemic authority of scientific/technical knowledge' (Carvalho and Nunes, 2013).

In the consulting room, in particular, MDs are often criticised for cultivating a patriarchal patient-doctor relationship which traditionally promotes relatively limited participation in decision making over treatment. Consumerism and the push for 'patient choice' in healthcare, most recently, promote, in contrast, more equal forms of interaction and aim at restraining physicians from defining the terms of communication with patients (Mold, 2013). Similarly, physicians may define the terms of engagement and the behaviour they will adopt towards members of other occupations they work closely with. Power asymmetries in the form of subordination of other groups in the division of labour are grounded on the perpetuation of a successfully promoted image of other occupations as inferior. For example, nurses are traditionally offering 'an adjunct service supporting real curative (medial) processes' (Salhani and Coulter, 2009: 1223); medical doctors often pass on to them tasks perceived as 'dirty' (Freidson, 1988); and exercise control over their work and training. In response, nurses often show a form of deference to MDs (Keddy et al., 1986; Porter, 1993) or, most recently, may try to 'decisively differentiate nursing from medicine' and mitigate power asymmetries through 'the continuing development of a theoretical and research base intended to clarify nursing knowledge' (Salhani and Coulter, 2009: 1223). Another intriguing relation is the one between MDs and pharmaceutical enterprises, with commentators mainly focusing on the legal and moral concerns raised by the commercial aspect of their interaction (Margolis, 1991). In particular, pharmaceuticals 
offer MDs minor or expensive gifts, free lunches, and the sponsoring of educational activities, conferences, and trips. MDs then decide to what extent they accept such provisions alongside the commercial aspect in their relation. The interests for pharmaceuticals lay to the influence they exercise upon MDs' pharmaceutical choice through presents (Peay and Peay, 1988; Halperin et al., 2004) given that the latter directly control drug consumption and, thus, affect drug sales and industry profits. Again, as in the patient-doctor or nurse-doctor relationships, MDs' legal and exclusionary right to define illness and therapy (in this case prescribe drugs) promotes a relation with a key stakeholder in the supply chain in which, irrespective to moral concerns, MDs can define the degree of engagement.

The literature carefully highlights, however, that professional dominance is 'contextual' in nature (Light, 1995: 26), therefore renegotiated as changes occur in the socio-economic environment (Dent, 2007; Light, 1995). This paper looks into the challenge facilitators pose to medical professionals in Greece trying to internationalise their services. As newcomers in the field, facilitators wish to partner with providers; and get a commission; the business to business relation does not include, however, a special position for medics. The relationship may, first, foster market competition with providers that use the same facilitators in a range of countries. Some of these facilitators grow much greater in size and turnover than the small/medium medical practices they work with. They may contract large or small medical providers internationally according to their changing interests or demand fluctuations; proving that international competition is stiff and scarcity in medical skill unimportant within the niche market. The power of facilitators to aggregate the (international) supplyside mitigates, thus, the power of medical professionals to set the terms of their engagement. The sociology of the professions anticipates that medical professionals are inclined to project power asymmetries in the new context whilst this paper offers evidence of medical professionals in Greece trying to reassert the authority of medicine in a sphere where it proves to have little currency; as such MDs-owners of private practices who seek to internationalise their services are alarmed by the increased options and negotiating power of (mainly referral but also full service) facilitators they are in contact with. 
Moreover, the transnational healthcare sector is entwined with a demand for additional services in comparison to domestic provision; complementary to medical care and yet inextricably linked to medical travel, so that the problem of how (by whom and under what circumstances) these will be offered emerges. In particular, small in size medical practices run by MDs need skill in international patient management, advertising, and networking in order to internationalise, tasks for which MDs traditionally have no training. The need thus to bring in skill and/or collaborate with facilitators to undertake tasks and responsibilities in the international context implies dependency. Simultaneously, the ability of facilitators to aggregate the demand side implies that it is professionals that wish to gain access to facilitators' client base (in a reverse situation to the one with pharmaceuticals, for example) which implies lack of leverage in negotiations. Furthermore, for as long as facilitators bring in clients, they have room to intervene in the patient-doctor relationship by setting service requirements to providers, and by promoting a self-claimed patient advocacy role for themselves (Snyder et al., 2011). As such, the international market appears significantly different than the national health provision; resources and tactics may need significant adaptation if professionals are to expand their privileged position in the internationalised context in the long-term. While professionals often act collectively, this piece of work focuses on the uncoordinated reaction of MDs in Greece to what is perceived as pressure from another actor. Against the backdrop of increased competition and lack of a true representative body, coordinated action is inhibited. Yet, the tacit self-understanding of MDs as incumbents puts them into a position to negotiate and, to a great extent, maintain a similar line of action vis-a vis medical tourism facilitators.

\section{HEALTHCARE IN GREECE: ORIENTATION TO EXPORTS \& MEDICAL}

\section{DOMINANCE}

Though a latecomer, Greece is increasingly engaging in the medical tourism market. As in renowned Asian destinations (Thailand and Malaysia, see Chee, 2010), the recent crisis has given strong incentives to various stakeholders to consider the potential of internationalising the domestic healthcare sector. For the last two years, seminars, mini-conferences, and other events on medical 
tourism are increasingly organised, emphasing that the idea of healthcare exports has matured ${ }^{1}$. A number of large private hospitals in the country have recently started developing a strategy (e.g. research, aesthetic and reconstructive plastic surgery, fertility treatment, dental care, physiotherapy, orthopaedic, bariatric and eye surgery are services offered to foreigners visiting Greece for healthcare. MDs' initiatives and incentives with regards to internationalisation of their services are characterised as entrepreneurial and profit-driven (Skountridaki, 2015). In particular, MDs take advantage of networks they have developed: first, with foreign patients during previous working experience abroad; and second, with colleagues in foreign countries they may know from conferences or international training (Skountridaki, 2015). Moreover, several advertise their services online, collaborate with facilitators, or have a representative in a foreign country (Skountridaki, 2015). To place these initiatives and the argument of this paper in the Greek context it is vital to illustrate the prominent position of MDs within the country.

MDs in a number of countries have experienced significant pressures leading to partial loss of control over the function of the healthcare sector. These include corporatism, managerialism, insurance companies' increasing role (Domagalski, 2007; Scott, 2008), but also consumerism which is related both to commercialisation (Timmermans and Oh, 2010) and liberation from the traditionally patriarchal patient-doctor relationship (Mold, 2013). In Greece (though research is limited) it can be argued that such pressures are relatively weak (Andri and Kyriakidou, 2014). Some change is evident within the public sector in the debt crisis era (Andri and Kyriakidou, 2014). Yet, there is little

\footnotetext{
${ }^{1}$ For example, medical tourism conferences (e.g. Developing Medical Tourism in Greece 2012; Greek Health Tourism Integration Conference 2014); seminars advising MDs how to promote their services abroad (e.g. Dental Tourism Awareness Day, Athens 2015); conferences organised by the Ministries of Health and Tourism announcing plans and progress on policies (e.g. Medical Tourism in Practice, Athens, 2013 and Medical Tourism in Practice, Thessaloniki 2014); streams in business exhibitions (e.g. the Money Show 2013) or in medical conferences, where business experts and success stories of medical professionals share their experience and knowledge. Participants and presenters are international business experts; medical doctors; facilitators; hospital managers; researchers/academics, hoteliers and government officers.
} 
indication of significant pressures exercised by external actors on MDs practicing privately, other than competitive forces (Skountridaki, 2015).

Greece has a profitable private healthcare sector and simultaneously an inefficient national system that since it was established back in the 1980s never fulfilled its aim to provide free public service (Cabiedes and Guillen, 2001). The main reason is that the clientelistic nature of the doctorpatient relationship did not cease after the creation of the Greek National Health care Service (NHS) but instead took the form of illegal informal payments, giving rise to corruption (Cabiedes and Guillen, 2001). Simultaneously, since the1980s the number of physicians grew rapidly; 2011 data show that Greece has almost double the OECD average in practicing physicians and more than double the UK and US ratio, ranking first among all OECD countries with 6.14 physicians per 1000 inhabitants (OECD, 2014). More than 58\% of these physicians are specialist medical practitioners. General practitioners in contrast, constitute less than $5 \%$ of the total, the lowest percentage among OECD countries. The remaining 37\% of MDs has no specialisation or wait in the long lists for specialisation (OECD, 2014). With regards to specialists, the large majority in Greece (65\%) comprises the backbone of the private sector; solo private practices have been estimated at more than 20 thousand back in 2005 (Tountas et al., 2005). Today, there are over 22 thousand private practices in Greece (excluding the nearly 14 thousand dental practices) according to online information provided by the Greek Ministry of Health (2015). While MDs working as public servants (e.g. in public hospitals) cannot practice privately, private practitioners may be contracted by the national insurance fund for a predefined number of consultations per month and a fixed fee.

It is also interesting to note the relation between private practitioners and private hospitals. Most often private hospitals' founders and shareholders have been (groups of) medical doctors; it is only recently that businessmen entered the healthcare sector (Economou, 2010). Moreover, MDs traditionally maintain a provider-client relationship with private hospitals instead of a salaried one. MDs typically hold their private practice and use hospital facilities (operation theatres, medical equipment, diagnosis services) on a case by case basis. Patients directly visit small practices; therefore, MDs have control over private expenditure and the model is one where the supply induces the demand with financial benefits for doctors, hospitals and diagnostic centres in the private sector. 
464 Supply-induced demand is identified as a major issue within healthcare provision in Greece

465 (Economou, 2010, Skalkidis et al., 1996; Tountas et al., 2005). Unsurprisingly, private healthcare

466 expenditure as percentage of GDP is high (3.2\%), ranking second among the OECD countries

467 (OECD, 2014). Financing of private healthcare comes from private and public expenditure with the

468 latter being considerably lower than the first (Economou, 2010). Therefore, it is basically private

469 expenditure that covers costs in the private sector directly paid by patients out of pocket; according to

470 Economou (2010: 47) only $2.1 \%$ of total health expenditure is covered by private insurance.

471 In summary, MDs play an active, arguably entrepreneurial role in the private healthcare

472 provision in Greece (Skountridaki, 2015). MDs are the owners of many private hospitals; and the

473 majority maintain a loose collaboration with private hospitals instead of a salaried relation; combined

474 with an absence of private insurance companies (that usually audit medical expenditure), private

475 practitioners in Greece have effectively managed to avoid external pressures from key players in

476 healthcare (Skountridaki, 2015). Yet, in the post-crisis era pressures are placed on MDs by market

477 competition. Competition is exacerbated by the curbed domestic demand due to a dramatic decrease

478 in the disposal income of locals (OECD, 2014a), coupled with an oversupply of MDs (OECD, 2014b)

479 concentrated in urban areas. It is notable that MDs have created a strong current of outward migration

480 during the last few years exceeding the number of 7500 practitioners between 2010 and July 2015

481 (Kathimerini, 2015). Within that context, internationalisation among practitioners and private

482 hospitals increasingly gains popularity.

\section{METHODOLOGY}

The empirical findings of this paper are based on semi-structured interviews conducted in Greece in 2012. Participants included 32 health professionals working in private practices. Medical professionals specialised in plastic surgery, ophthalmology, In Vitro Fertilisation (IVF), dental care, and cardiac surgery. Interviews were also conducted with a psychologist and a midwife and two hospital managers. MDs interviewed are well-respected professionals compensated on a fee-forservice basis. Medical professionals work exclusively in the private sector as solo practitioners or in small partnerships; three also hold offices within a private hospital but maintain their personal website. At the time of fieldwork, hospitals had not yet developed a strategy with regards to 
international patients/markets; the interviewees counted on their own reputation and efforts to attract foreign patients. Some hospital groups, however, closely followed the international developments and were in the process of developing a strategy or examining the prospects. In contrast, public providers in Greece have not taken any steps in internationalising their services, whilst, to the best knowledge of the author, the Ministry of Health has not announced a plan to do so in the future. All interviewees, except for three, had specialisation training and/or work experience in other Western countries, mainly the UK and USA.

To enlist potential interviewees, an online search was conducted through the Google search engine using keywords such as 'surgery', 'treatment', 'dental care' in combination to location names (i.e. 'Athens', 'Crete', 'Rhodes'). The online search was exhaustive with respect to locations, i.e. the researcher looked all over Greece for potential interviewees. The search showed that practices advertising services to foreign patients are in the urban centres of the country where medical facilities are mainly concentrated (Athens and Thessaloniki) and on a few of the islands or coastal regions. Therefore, participants were approached in Athens, a metropolitan area, and the island of Crete, an area in the periphery with relatively good healthcare facilities and high international tourism demand. The interviewees were approached based on their professional webpage and the criterion employed was whether the website has a version in foreign language(s). This was perceived as a sign of interest in foreign markets. Only in two cases was there no real interest. The number of MDs fulfilling the criterion was at the time slightly exceeding one hundred for Athens and Crete. This implies that the number of 32 interviews is a satisfactory sample. While Greece has yet to develop a booming industry, patients travel to Athens or Crete for healthcare from a wide range of countries. Countries mentioned most often during the interviews are UK, Cyprus, Scandinavian countries, and the USA. Interviewees mention to a lesser extent people visiting from Australia, Canada, Italy, France, Belgium, Germany, the Netherlands but also Middle East and N. Africa.

Interviewees were approached either through email, telephone, or through a short visit to their working place where the interviewee had the chance to briefly meet them in-between their medical appointments and explain the aims of the study in person. The interviews took place in the working space of the interviewees except for one which took place in a central café in Athens. One interview 
was in English as the participant does not speak Greek, with the rest of the interviews conducted in

521 Greek. Interviews lasted from 20 minutes to two hours, were transcribed, and then translated in

522 English where needed. Though most interviewees were not familiar with qualitative research, they were welcome and open to share their experiences and perspective. In few cases, rapport was established after the first 10-15 minutes of discussion, whilst all participants were interested in the research topic. The semi-structured interview guide included questions on perceptions about the phenomenon of medical tourism broadly and in Greece in particular; perceptions on the developments forging the sector currently and in the future; and personal experiences with various actors such as foreign patients, the state, and facilitators. Given the exploratory nature of this research, in depthinterviews are deemed suitable as they allow room for participants to express themselves in their own words (May, 2001:121), and helps the researcher look into their 'own perspective on their lived world' (Kvale, 1996: 105), and their layered motives and beliefs, within contextual complexity (Cavaya, 1996).

After the interviews were transcribed the researcher became immersed in the data, reading the interviews multiple times and comparing perceptions and views. Repeated themes had a number assigned and were then organised into several logical thematic parts distinguished into contextrelated; perception-related; and processes or events that affect the evolution of developments (Wiersma, 1995: 217). After interrelating them with insights from the sociology of the professions, three major themes emerged. As most participants shared their experiences with facilitators, their relationship came across as a major discussion topic. The dissatisfaction towards facilitators was not anticipated, which highlights the role of qualitative research into generating genuine insights in aspects of real life phenomena (Patton, 2002). Following the logic of abduction, insights were framed through theory; arguably, 'facts do not speak for themselves; they must be interpreted' (Denzin, 1978 cited in Patton, 2002). Here, the micro-politics between professionals and facilitators are largely conceived within the framework of professional dominance, according to which professionals tend to impose their control over the work of other actors in healthcare supply (Freidson, 1985). and some have Greek representatives. They rarely refer to local facilitators, implying limited local 
business activity. All participants except for two had communicated (via emails, calls or in person)

549

550

551

552

553

554

555

556

557

558

559

560

561

562

563

564

565

566

567

568

569

with at least one facilitator. Three interviewees had collaboration with facilitators earlier than 2006 , and the rest have been in contact with facilitators typically after 2007-2008. Some never entered into agreement after seriously considering the prospect or interrupted collaboration; and yet all participants but one state that they are interested in intermediating and advertising services. Interviewees discuss about referral rather than full service facilitators (Table 1) - while there is no evidence to suggest that 'individual' facilitators operate in Greece (Dalstrom, 2013). MDs mainly refer to web portals that list medical providers in multiple destinations and do not provide travel and/or medical arrangements to patients. Nevertheless, a plastic surgeon refers to a terminated collaboration with a full service facilitator, a one-man company operating in the UK; while a dental surgeon explains he turned down an offer of a full service facilitator but collaborates with referral facilitators; and a third one collaborates with a full service facilitator but no 'brokers'. While findings may be inconclusive about whether MDs have a preference for one type of facilitators over the other, the rationale behind their course of action is underlined by an effort to maintain control over the business relation.

Table 1. Study participants

\begin{tabular}{lccc}
\hline Specialisation & No & $\begin{array}{c}\text { Past/present Collaboration } \\
\text { with referral facilitator }\end{array}$ & $\begin{array}{c}\text { Past/present Collaboration } \\
\text { with full-service facilitators }\end{array}$ \\
\hline Cardiac surgeons & 2 & 1 out of 2 specialists & - \\
Plastic Surgeons & 9 & 5 out of 9 specialists & 1 out of 9 specialists \\
Eye surgeons & 2 & 1 out of 2 specialists & - \\
Dental Surgeons & 9 & 4 out of 9 specialists & 2 out of 9 specialists \\
IVF specialists & 6 & 3 out of 6 specialists & 1 out of 6 specialists \\
Hospital Senior Managers & 2 & 1 out of 2 hospitals & 1 out of 2 specialists \\
Psychologist in IVF clinic & 1 & N/A & N/A \\
Midwife in IVF clinic & 1 & N/A & N/A \\
\hline
\end{tabular}

There are two limitations that need to be acknowledged. First, not all participants referred to their relationship with facilitators. A small minority had no form of collaboration or seemed to have no concern from their interactions. Moreover, the findings could possibly gain further insight from examining the perspective of facilitators with regards to their interactions with MDs in Greece. This would potentially give a more rounded view of their relationship and it is the aim of future research.

\section{MDs' PERCEPTIONS OF FACILITATORS}


As described earlier, dominance is a term employed to refer to subordination of other occupations

571 in healthcare provision. It emphasises dominance in the division of labour where nurses, pharmacists,

572 technical and often administrative personnel 'were obliged to work under the supervision of

573 physicians and take orders from them' (Freidson, 1985: 13). Interviewees' accounts, analysed under

574 the dominance narrative, are presented in three sub-sections. First, it is shown that after the initial

575 contact between the agent and the practice, a business relationship is often established. It is then

576 highlighted that the attitude of professionals towards facilitators has two dimensions; on the one hand,

577 the latter are deemed necessary, and on the other, they are met with suspicion. Finally, it is

578 demonstrated how suspicion soon turns to politics and professionals often deny or stop collaboration.

\subsection{Establishing a Relationship}

580

When MDs describe the initial push factor to turn to foreign clientele it becomes obvious that medical tourism facilitators have played a crucial role. Following a number of interviews it became clear that facilitators, mainly web-based companies from the UK, have approached a significant number of MDs in Greece. Facilitators often inform MDs about developments in the field (international business fairs, changes in EU law, findings of relevant surveys etc.) and at the same time promote their services (online marketing services or representation to foreign markets etc.). A dental surgeon explains:

'They call you to international conferences for medical tourism, they inform you about exhibitions you may join [...] until 2008 the emails I would receive from such companies were almost more than the emails I would get from patients' (Dental Surgeon A).

The search for partnership is bidirectional; professionals also initiate contact and may advertise their mentions,

'I use a company [...], I use it now for six, seven years, perhaps even more... when they were starting, I was starting too. And it has helped me a lot...' (Plastic Surgeon A). 
When asked about their perceptions of facilitators, medical doctors acknowledge that their role is crucial in channelling patients to their practice. MDs may have limited knowledge over foreign markets and, considering the relatively small size of their practices, it may not be easy to reach out to a sizable pool of overseas patients.

'There was a need and they were created [...] they simply facilitate the whole operation, because a website needs a lot of referrals to be found in a good position in Google results. An independent site like ours, for example, cannot appear high. Theirs $[\ldots]$ has many referrals and it is easier to find audience' (Plastic Surgeon A).

Facilitators' services are therefore valued; after all facilitators undertake tasks physicians often have no time, knowledge, or skill to do. Several medical professionals discuss how they are too busy with patient consultation and treatment, leaving no time for the promotional efforts of the practice. Some also confess that their skills are restricted to medicine and marketing is a task they are not trained for. While they acknowledge the importance of promotion, others explain they are not willing to be personally involved in the marketing process as it is a dull task that offers little job satisfaction. It often comes down to the same conclusion about facilitators,

'So they are necessary. They are necessary to bring people in. A man cannot do everything. I am for example a doctor [...] I do not have the time, knowledge, the ability to do everything' (Dental Surgeon J).

Knowledge plays a significant role in professional politics as it defines the boundaries of work (Abbott, 1988). In particular, professionals maintain exclusive rights to perform tasks based on their recognised expertise in an area. Internationalisation of the market, however, demands a new set of skills that medical professionals realise they do not possess. Within the dynamic environment, thus, an occupational vacancy is created (Nancarrow and Borthwick, 2005), changing the established boundaries of work. In this case the vacancy is not related to medical skills; core tasks such as drug prescription, diagnosis, or treatment are not contested. The vacancy concerns brokerage and marketing.

Nonetheless, MDs appear reserved and cautious. Their expectations of facilitators are not fulfilled for a variety of reasons. Professionals often refer to unrealistic promises in the expected outcomes by 
facilitators or express scepticism over the way patient inquiries are handled; discouraging a number of professionals from establishing collaboration.

'So they choose providers... after I paid the fee they told me they have three IVF centres in Athens that they refer clients to. But how? Rotationally? I am not sure how it works...I am not even sure whether all inquiries were real or set up. There is no way I can know that' (IVF expert A).

Information asymmetry potentially passes control to agents over prices, the services, and the choice of providers. Medical professionals often feel there is lack of transparency in the pricing and advertising practices of facilitators and no information mechanisms to monitor their activities. These attitudes demonstrate alienation to the way facilitators run their business and, close to this, dissatisfaction or hesitation. It is notable, however, how such attitudes conceal a latent contestation over who controls the terms of collaboration. The excerpt below shows how the quoted professional insinuates little understanding of the pricing strategy of a referral facilitator right after he describes it in quite some detail. Though not stated explicitly, hesitation is arguably a matter of politics, 'There is an issue with how they function. They say I advertise you, yes, but if you want to be advertised a bit better, you will have to give me more money [...] or I will advertise you for free but from all incidents you get you will give me $15 \%$ of the revenue, all these are a bit dodgy... it is not clear how it works' (Dental surgeon $\mathrm{H}$ ).

\subsection{It Soon Turns To Politics}

Relatively quickly, the expression of hesitation and doubt turns explicitly to politics. Several MDs realise that a new actor may gain power over their work. The sociology of the professions explains how professionals strive to maintain control over the organisation, distribution, and trade of their production (Larson, 1977; Abel, 1988). The special relationship between the doctor and the patient has been also analysed as a facet of medical power (Hughes, 1958); characterised as intimate and paternalistic, one where MDs define the terms of communication (Carvalho and Nunes, 2013). It is exactly such balances that 'medical tourism' facilitators threaten to disrupt. It is the facilitators' role to mediate between the patient and the doctor, through this they influence the rules of trade, the fees, and to some extent the conditions of work of medical professionals. Unsurprisingly, most participants feel challenged by the necessary, albeit intrusive, new actor. A dental surgeon explains that facilitators 
653

654

655

656

657

658

659

660

661

662

663

664

665

666

667

668

669

670

671

672

673

674

675

676

677

678

are useful for his practice, but appears dismissive of mediating services that go beyond simple advertisement and referrals. The doctor-patient relationship is of strategic importance for MDs, and a third party intervening is not particularly welcome; initiatives for patient handling and further involvement are dismissed as irrelevant.

'For example, someone wanted to create a website; to choose specific MDs; provide specific services and be the manager of the whole thing. Because obviously wherever there is money everybody wants to get involved [...] but to my mind the level of doctor-patient is so personal that the success of such a thing is particularly difficult' (Dental Surgeon D).

Furthermore, micro-level autonomy refers to the right of professions to define their fees and own conditions of labour (Flynn, 1999: 22). Medical professionals comment on how facilitators challenge these aspects of their autonomy, resenting a relationship of dependence. No matter how necessary, dependence upon facilitators concedes leverage which is a cause of concern.

'Since Greece has not established a brand name for medical tourism, you have to be involved in the process of collaborating with them in terms that they define and you have to follow' (Cardiac Surgeon A).

Some professionals acknowledge that 'brokers' obtain power as they offer intermediary services which go beyond informational services. Portals in particular offer a ready platform which numerous providers may easily join for an annual subscription or payment per reference. Facilitators may contract medical providers in a range of destinations revealing that international competition is stiff and scarcity in medical skill unimportant within the niche market. As a result, professionals who seek to internationalise their services are alarmed by the increased options and the negotiating power of facilitators they are in contact with,

'See for example what happened to hoteliers in Crete... the tourism agents push them hard to reduce their prices...they say we don't care...we will send our customers to Turkey or Spain...imagine this happening to dental care! So, as you see, one ought to be careful with intermediaries' (Dental Surgeon J). 
Another surgeon mentions friction as inhibiting collaboration and addresses the issue of power and control. Fees and commissions are often perceived as high; but who defines the fees clearly plays an important role,

'They [colleagues] talked with some companies from the UK and could not agree in prices. Namely, they considered the commission the office would take was extremely high; we do not want to work in dependence. Most MDs, this is how they work, and most MDs in [name of hospital]...this is why it [the hospital] was created, it belongs to doctors. We do not have agreements with insurance companies, funds etc., so that we define our price. If we get into the process that others define our reward, eh, there we do not really like the thing...if we do not agree. And this is where collaboration stops' (Plastic Surgeon G).

Characteristic is the example of another professional (plastic surgeon F) that does not hesitate to stop collaboration with a representative in the UK who has been his basic source of patients for several years. He suggests that the agent started secretly to charge a high fee to each patient, which was exceeding his own and, consequently, reacted by interrupting collaboration.

\section{Even when medical professionals control the division of labour, their efforts to maintain control} must be constant (Abbott, 1988: $71 \& 73$ ). The decisiveness in interrupting or turning down collaboration with facilitators is part of the maintenance process. Expanding to a new market where their dominant position is not sustained does not appear a good option. Looking at it from another perspective, the stance of MDs functions as an impediment for facilitators that wish to penetrate the Greek market and potentially aggregate the supply-side. Though MDs understand the importance of intermediating services they hesitate to rely on facilitators even when they appear as a viable readyavailable way to expand to foreign markets. If they would not be dissatisfied facilitators would have a better access to the Greek supply-side and, therefore, the share they typically require (15-20\% according to interviewees) from the related patient expenditure. For as long as collaborations are interrupted, penetration to the Greek supply is delayed or inhibited. Negotiating commission and other rules may appear particularly provocative to Greek private practitioners who are not used to managerial or financial control by third parties. As discussed earlier, neither the private hospitals as 
employers, nor insurance funds as payers, have done so until today. A manager working in one of the two largest hospitals in the country explains that,

'Clients of the hospital are not the patients. The doctors are. They bring patients into the hospital and they get paid for that' (Senior Manager B).

In that sense it is not surprising that medical professionals feel threatened by the interventions of the facilitators. The question over what professionals ideally want from facilitators remains. The overall impression is that they are content to work with facilitators when their fees are low; or when facilitators are exclusive representatives. It is also interesting to note that specialisation does not account for differences in response to facilitators; both dental and plastic surgeons, and gynaecologists are vocal in expressing their concerns. The reaction of MDs in Greece highlights how institutional inertia supports the continuation of professional dominance amidst contextual changes. MDs engaging in a young, niche market attempt to disrupt the growing power of facilitators in its infancy; as Netting and Williams suggest 'old habits die hard' (1996).

\section{CONCLUSION}

With services gaining increased importance in global production, international trade in services flourishes (Sako, 2013), and healthcare forms no exception. Yet, the transnational healthcare business sector appears far from settled. Health insurance is largely confined to national borders, medical providers are increasingly internationalising changing the global supply map, and the intermediaries' business sector is unstable and, to an extent, unreliable (Cormany and Baloglu, 2010; Turner, 2012). Within Europe, despite the Directive on Patient Mobility, Greer and Rauscher (2011) describe developments as 'negative integration' as opposed to market formation, emphasising the impediments in intra-European trade. This paper has examined an aspect of market development which highlights the meeting of medical providers in Greece orientated to the internationalisation of their operations with specialised agents. As such it pays attention to small medical practices in their path to internationalisation as opposed to large, resource-rich organisations (hospitals) in the supply chain. The problem identified pertains to the ambivalence of medical professionals towards facilitators. This ambivalence is disentangled through the conceptual framework of the Sociology of the Professions, leading to a theory-informed insight into why trust is difficult to establish between the two actors. 
According to the Sociology of the Professions, MDs typically work in relations characterised by

735

power asymmetries titling to their favour. Drawing on their expertise they set the terms of engagement and define the behaviour they adopt towards other stakeholders in the delivery of healthcare. In this study, MDs acknowledge that facilitators have increased leverage in their business relation. The leverage that facilitators have is based on their ability to aggregate the supply side (and thus expose MDs to international competition with both small and large providers across a number of countries); the ability to aggregate the demand-side (and thus have control over a client base MDs wish to have access to); and by association the opportunity to intervene in the patient-doctor relationship (by defining conditions of communication/interaction between patient and doctor or as patient advocates). As such, the development of a facilitator-MD relation understood as mutually beneficial is undermined and MDs in Greece often interrupt collaboration (Figure 1). Practically, this implies delays in the internationalisation path of MDs; less chances for facilitators to further collaborations; and, thus, slower development of the market. Lee and Fernando (2015) analyse the 'medical tourism supply chain management' in Malaysia and highlight the significance of trust and commitment among business partners. They suggest that, though first efforts to develop the sector in Malaysia date back to 1997, 'a lack of understanding of the advantages brought about by the medical tourism supply chain still plagues the industry' (2015: 155). This paper offers insight, to practitioners and scholars alike, into why trust between two of the supply-side key actors, in a different geographical area, has been a challenge. The findings show how professional norms and expectations may work out as factors dissuading the development of the market (Ormond et al., 2015); establishing mutually advantageous relations between 'business' partners in a new field cutting across borders and two industries (health care and tourism) may prove demanding; in Greece it arguably involves deliberations by medical professionals underpinned by healthcare micro-politics.

Overall, the international business arena appears attractive but bears challenges for medical professionals. The fact that numerous small practices in Greece (and elsewhere) strive to internationalise their services shows the potential for further market expansion. Yet, the new environment functions under different rules and incentives as Glinos et al. (2010) aptly comment, and this paper offers insight into how medical professionals orientated to the internationalisation of their 
operations experience these new dynamics. As such it informs the sociology of the professions of new market-driven challenges for MDs engaging in international trade. The global market increases competition as scarcity of medical skill is surmounted; and emphasises the entrepreneurial and business aspect of medical services. It denudes MDs of their social role which typically fortifies their position and strengthens their influence over policy-makers. Consequently, the ability to negotiate terms and conditions for their services when they confront facilitators in the internationalised context is further attenuated. Perturbed by these dynamics, MDs explore trade options with caution; while their motives are financial, long established relations that underpin continuing medical dominance are carefully considered.

While it is difficult to generalise conclusions without comparative studies, findings remain informative and relevant to destinations beyond Greece, where facilitators come in direct contact with medical professionals running small medical providers. Participants discuss, after all, how numerous agents get in touch to advertise their services and explore opportunities for collaboration. As facilitators routinely contact numerous practitioners in different destinations, similar issues may very well arise elsewhere, leading MDs and facilitators to an arduous search for business partners.

The findings are also relevant to tourism practitioners. Healthcare politics may be all too familiar (no less due to lived experiences) to public sector practitioners, managers in private/public healthcare organisations, and policy makers in a number of countries. There is nothing new with the idea and practice of MDs striving to perpetuate privilege in their changing relations. In contrast, actors with little background in healthcare provision are naturally less endowed to reflect on healthcare politics and professional norms. After all, MDs working for large private hospitals do not deal with facilitators and, therefore, the issues discussed in this study are not observed. In light of this, it may be hard for facilitators (or practitioners in the tourism sector) to understand why an MD would not continue with a profitable collaboration, as this study suggests. Business is about profit. Professionalism, in contrast, is much more than that, even when privately practiced and driven by profits. By association, it is hard to reduce MDs to business people the very moment they try to internationalise their services. This study encourages, thus, tourism practitioners (including facilitators) to consider certain aspects in MDs' stance and behaviour as emanating from pre-existing professional norms and attitudes within 
the healthcare sector. More broadly, interdisciplinary endeavours often challenge those involved due to lack of basic understanding of diverse logics dominant in different sectors. Tourism practitioners are, thus, encouraged to consider that MDs prioritise the ability to define their own fees and terms of communication, strive to maintain an intimate relation with patients, and to avoid control over their content of work in any possible way.

\section{REFERENCES}

Abbott, A. (1988) The system of professions: An essay on the division of labor. Chicago: University of Chicago Press.

Abel, R.L. (1988) The Legal Profession in England and Wales. New York: Blackwell. Ackerman, S.L. (2010) Plastic Paradise: Transforming Bodies and Selves in Costa Rica's Cosmetic Surgery Tourism Industry. Medical Anthropology: Cross-Cultural Studies in Health and Illness, 29, 4, 403-423

Andri, M. and Kyriakidou, O. (2014) Professional autonomy under pressure: towards a dialectical approach, Journal of Health Organization and Management, 28, 5, 635 - 652 Barrowman, A., Grubor, D. and Chandu, A. (2010) Dental Implant Tourism. Australian Dental Journal, 55, 4, 441-445

Bell, D., Holliday, R., Ormond, M., and Mainil, T. (2015) Transnational healthcare, cross-border perspectives, Social Science \& Medicine, 124, 284-289

Birch, D.W., Vu, L., Karmali, S., Stoklossa, C.J. and Sharma, A.M. (2010) Medical tourism in bariatric surgery. The American Journal of Surgery, 199, 5, 604-608

Bolton S. and Skountridaki L., The Medical Tourist and a Political Economy of Care, Antipode 49 (2), 2017

Cabiedes, L. and Guillén, A. (2001) Adopting and adapting managed competition: health care reform in Southern Europe. Social Science \& Medicine, 52, 8, 1205-1217

Carrera P and Lunt N (2010) A European perspective on medical tourism: The need for a knowledge base. International Journal of Health Services, 40, 3, 469-84

Carvalho, A. and Nunes J.A. (2013) Technology, Methodology and Intervention: Performing Nanoethics in Portugal. NanoEthics, 7, 2, 149-160

Caulfield, T. and Zarzeczny, A. (2012) Stem cell tourism and Canadian family physicians. Canadian Family Physician, 58, 4, 365-368

Cavaya, M. (1996) Case study research: a multi-faceted research approach for IS. Information Systems Journal, 6, 3, 227-242

Chantarakarn C, Foley S, James W, and Pandey R, (2013) Medical Tourism in Arizona. Thunderbird School of Global Management, Arizona. 
824 Chee, H.L. (2010) Medical tourism and the state in Malaysia and Singapore. Global Social Policy, 10, $825 \quad 336-357$

826 Cheung, I.K. and Wilson, A. (2007) Arthroplasty tourism. MJA, 187, 11/12, 666-667

827 Chuang, TC., Liu, JS., Lu, LYY., and Lee, Y. (2014) The main paths of medical tourism: From

828 transplantation to beautification. Tourism Management, 45, 49-58

829 Connell, J. (2013) Contemporary medical tourism: Conceptualisation, culture and commodification.

830 Tourism Management, 34, 1-13

831 Cormany, D. and Baloglu, S. (2010) Medical travel facilitator websites: An exploratory study of web

832 page contents and services offered to the prospective medical tourist. Tourism Management, 32, 709-

$833 \quad 716$

834 Crooks, V., Turner, L., Snyder, J., Johnston, R. and Kingsbury, P. (2011) Promoting medical tourism

835 to India: Messages, images, and the marketing of international patient travel, Social Science \&

836 Medicine, 72, 726-732

837 Crush, J., Chikanda, A., and Maswikwa, B. (2012) Patients without Borders: Medical Tourism and

838 Medical Migration in Southern Africa. Cape Town: Southern African Migration Programme (SAMP).

839 Dent, M. (2007) Medicine, Nursing and Changing Jurisdictions in the UK. In Muzio, D., Ackroyd, S.,

840 Chanlat, J.F. (eds) Redirections in the Study of Expert Labour. Basingstoke: Palgrave. pp. 101-117

841 Dalstrom, M., 2013. Medical travel facilitators: connecting patients and providers in a globalized

842 world. Anthropology and Medicine, 20, 1, 24-35.

843 Domagalski, T. (2007) Organization and subjectivity in the US medical profession: Physician

844 responses to structural changes within advanced capitalism. In Muzio, D., Ackroyd, S. and Chanlat,

845 JF. (eds) Redirections in the Study of Expert Labour. Basingstoke: Palgrave. pp. 118-138

846 Doolin, B. (2002) Enterprise Discourse, Professional Identity and the Organizational Control of

847 Hospital Clinicians. Organization Studies, 23, 369-390

848 Economou, C. (2010) Greece: Health system review. Health Systems in Transition, 12, 7, 1-180

849 Fligstein, N. and McAdam, D. (2012) A Theory of Fields. Oxford University Press.

850 Flynn, R. (1999) Managerialism, professionalism and quasi-markets. In Exworthy, M. and Halford, S.

851 (eds) Professionals and the New Managerialism in the Public Sector. Buckingham: Open University

852 Press. pp. $18-36$

853 Foss, C.B. (2012) Editorial. Patients Have a Right to Safe Surgery. International Society of Aesthetic

854 Plastic Surgery, 36, 1-2

855 Frederick J. R. and Gan, L.L. (2015) East-West differences among medical tourism facilitators'

856 websites, Journal of Destination Marketing and Management, doi: 10.1016/j.jdmm.2015.03.002.

857 Freidson, E. (1985) The Reorganization of the Medical Profession. Medical Care Research and

858 Review, 42, 11- 35

859 Freidson, E. (1988) Profession of Medicine: a Study of the Sociology of Applied Knowledge. Chicago:

860 University of Chicago Press. 
861 Freidson, E. (1993) How Dominant are the Professions?. In Hafferty, F. and McKinlay, J. (eds) The

862 Changing Medical Profession: an International Perspective. New York: Oxford University Press. pp.

$863 \quad 54-66$

864 Freidson, E. (2001) Professionalism: The Third Logic. Cambridge: Polity.

865 Glinos, I.A., Baeten, R., Helble, M. and Maarse, H. (2010) A typology of cross-border patient

866 mobility. Health \& Place, 16, 1145-1155

867 Greer, S. L. and Rauscher, S. (2011) When Does Market-Making Make Markets? EU Health Services

868 Policy at Work in the United Kingdom and Germany. Journal of Common Market Studies. 49, 4, 797-

$869 \quad 822$

870 Hamilton, N. (2008) Assessing Professionalism: Measuring Progress in the Formation of an Ethical

871 Professional Identity. University of St. Thomas Law Journal, 5, 2, 101-143

872 Halperin, E.C., Hutchison, P. and Barrier R.C. (2004) A population-based study of the prevalence and

873 influence of gifts to radiation oncologists from pharmaceutical companies and medical equipment

874 manufacturers. Radiation Oncology, 59, 5, 1477-1483

875 Harrison, S. and Ahmad W.I.U. (2000) Medical Autonomy and the UK State 1975 to 2025. Sociology,

$876 \quad 43,1,129-146$

877 Hopkins, L., Labonté, R., Runnels, V. and Packer C. (2010) Medical tourism today: What is the state

878 of existing knowledge? Journal of Public Health Policy, 31, 2, 185-198

879 Hughes, E. (1958) Men and Their Work. London: The Free Press of Glencoe, Collier-Macmillan

880 Limited.

881 Inhorn, M.C. and Patrizio, P. (2009) Rethinking reproductive "tourism” as reproductive "exile”.

882 Fertility and Sterility, 92, 3, 904-906

883 Jarman, H. and Greer, S. (2009) Crossborder trade in health services: Lessons from the European

884 laboratory, Health Policy, 94, 2, 158-63

885 Jeevan, R. and Armstrong, A. (2008) Cosmetic Tourism and the burden on the NHS. Journal of

886 Plastic, Reconstructive \& Aesthetic Surgery, 61, 1423-1424

887 Johnson, T.J. (1972) Professions and Power, Macmillan, London.

888 Jones, J.W. and McCullough, L.B. (2007) What to do when a patient's international medical care goes

889 south. Journal of Vascular Surgery, 46, 1077-1079

890 Kathimerini Online Edition (2015) The great flee of doctors (in Greek)

891 http://www.kathimerini.gr/825077/article/epikairothta/ygeia/h-megalh-fygh-twn-giatrwn (last

892 accessed 15/01/2016).

893 Keddy, B. Jones Gillis, M., Jacobs, P., Burton, H. and Rogers, M. (1986) The doctor-nurse

894 relationship: an historical perspective. Journal of Advanced Nursing, 11, 6, 745-753

895 Kirkpatrick, I., Jespersen, P. K., Dent, M. and Neogy, I. (2009) Medicine and management in a

896 comparative perspective: the case of Denmark and England. Sociology of Health \& Illness, 31, 5,

$897 \quad 642-658$ 
898

899

900

901

902

903

904

905

906

907

908

909

910

911

912

913

914

915

916

917

918

919

920

921

922

923

924

925

926

927

928

929

930

931

932

933

Kvale, S. (1996) Interviews: An Introduction to Qualitative Research Interviewing. London, Thousand Oaks, New Delhi: Sage Publications

Labonté R. (2013a) Overview: Medical Tourism Today: What, Who, Why and Where? In Labonté R., Runnels, V., Packer, C. and Deonandan, R. (eds) Travelling well: Essays in medical tourism. Transdisciplinary Studies in Population Health Series, 4, 1. Ottawa: Institute of Population Health. Labonté R. (2013b) Let's Make a Deal: The Commerce of Medical Tourism. In Labonté R., Runnels, V., Packer, C. and Deonandan, R. (eds) Travelling well: Essays in medical tourism. Transdisciplinary Studies in Population Health Series, 4, 1. Ottawa: Institute of Population Health.

Lam, C., du Cros, H. and Vong, T.N. (2011) Macao's potential for developing regional Chinese medical tourism. Tourism Review, 66, 68-82

Larson, M.S. (1977) The Rise of Professionalism: A Sociological Analysis. Berkeley, CA: University of California Press.

Lee, H. K. and Fernando, Y. (2015) The antecedents and outcomes of the medical tourism supply chain, Tourism Management, 46, 148-157

Light D.W. (1995) Countervailing powers: a framework for professions in transition. In Johnson, T., Larkin, S. and Saks, M. (eds) Health Professions and the State in Europe. London: Routledge. pp. 2541

Lunt, N., Hardey, M. and Mannion, R. (2009) Nip, Tuck and Click: Medical Tourism and the Emergence of Web-Based Health Information. The Open Medical Informatics Journal, 3, 77-87 Lunt, N., Smith, R., Exworthy, M., Green, S.T., Horsfall, D. and Mannion, R. (2011) Medical tourism: Treatments, markets and health system implications: A scoping review. Paris: OECD. Lunt, N., Horsfall, D. Smith, R., Exworthy, M., Hanefeld, J. and Mannion, R. (2014) Market size, market share and market strategy: three myths of medical tourism. Policy and Politics, 42 (4), $597-$ 614

McKelvey, A., David, A., Shenfield, F. and Jauniaux, E. (2009) The impact of cross-border reproductive care huuor 'fertility tourism' on NHS maternity services. BJOG, 116, 1520-1523 McLaughlin, J. and Webster, A. (1998) Rationalising knowledge: IT systems, professional identities and power. The Sociological Review, 46, 4, 781-802

Macdonald, KM. (1995) The Sociology of the Professions. SAGE Publications.

Maheshwari, S., Animasahun, B., and O.F., N. (2012) International patients with congenital heart disease: what brings them to India?. Indian Heart Journal, 6401, 50-53

Margolis H.L. (1991) The Ethics of Accepting Gifts from Pharmaceutical Companies. Pediatrics, 88, 6

Mason, A. \& Wright, K. B. (2011) Framing Medical Tourism: An Examination of Appeal, Risk, Convalescence, Accreditation, and Interactivity in Medical Tourism Web Sites. Journal of Health Communication: International Perspective, 16, 2, 163-177 
934

935

936

937

938

939

940

941

942

943

944

945

946

947

948

949

950

951

952

953

954

955

956

957

958

959

960

961

962

963

964

965

966

967

968

969

970

Mattoras, R. (2005) Reproductive exile versus reproductive tourism. Human Reproduction, 20, 12, $3571-3573$

May, T. (2001) Social research: issues, methods and process. Philadelphia, Pa.: Open University Press.

Ministry of Health, Greece (2015) http://ygeiamap.gov.gr/ (last retrieved 15/01/2015)

Miyagi, K., Auberson, D., Patel, A.J. and Malata, C.M. (2011) The unwritten price of cosmetic tourism: an observational study and cost analysis. Journal of Plastic, Reconstructive \& Aesthetic Surgery, 65, 22-28

Mold, A. (2013) Repositioning the Patient: Patient Organizations, Consumerism, and Autonomy in Britain during the 1960s and 1970s. Bulletin of the History of Medicine, 87, 225-249

Nancarrow, S. A. and Borthwick, A.M. (2005) Dynamic Professional boundaries in the healthcare workforce. Sociology of Health \& Illness, 897-919

Netting, F.E. and Williams, F.G. (1996) Case manager-physician collaboration implications for professional identity, roles, and relationships. Health \& Social Work, 21, 216-224

OECD (2014b) OECD Factbook 2014: Economic, Environmental and Social Statistics. OECD

Publishing. DOI:10.1787/factbook-2014-table243-en

Ormond, M. (2015) Solidarity by demand? Exit and voice in international medical travel - The case of Indonesia, Social Science \& Medicine, 124, 305-312

Ormond, M., Lunt, N., and Connell, J. (2015) IMTJ Academic Conference on Medical Travel and Cross Border Healthcare: Call for papers. https://summit.imtj.com/academic-overview/ (last assessed $15 / 01 / 2016)$

Patton, M. Q. (2002). Qualitative Research and Evaluation Methods (3rd edn.). Thousand Oaks, California: Sage.

Peay, M.Y. Peay E.R. (1988) The role of commercial sources in the adoption of a new drug. Social Science \& Medicine, 26, 12, 1183-1189

Pimlott, N. (2012) Searching for Hope. Canadian Family Physician, 58, 4, 363

Penney, K., Snyder, J., Crooks, V.A. and Johnston, R. (2011) Risk communication and informed consent in the medical tourism industry: A thematic content analysis of Canadian broker websites.

BMC Medical Ethics, 12, 17, 1-9

Porter, S. (1993) Critical Realist Ethnography: The Case of Racism and Professionalism in a Medical Setting. Sociology, 27, 4, 591-609

Rosenmöller, M., McKee, M. and Baeten, R. (2006) Patient mobility in the European Union. Learning from experience. Copenhagen: European Observatory on Health Systems and Policies. Sako, M. (2013) Professionals between market and hierarchy: a comparative political economy perspective. Socio-Economic Review, 11, 1-28

Salhani, D. and Coulter, I. (2009) The politics of interprofessional working and the struggle for professional autonomy in nursing. Social Science \& Medicine, 68, 7, 1221-1228 
971 Scott, W.R. (2008) Lords of the Dance: Professionals as Institutional Agents. Organization Studies, 972 29: 219-238

973 Skalkidis, Y., Petridou, E., Papathoma, E., Revinthi K., Tongi, D., and Trichopoulos, D. (1996) Are 974 Operative Delivery Procedures in Greece Socially Conditioned?' International Journal for Quality in 975 Health Care, 8, 2, 159-65

976 Skountridaki L., The Internationalisation of Healthcare and Business Aspirations of Medical 977 Professionals, Sociology 49 (3), 2015, 471-487.

978 Snyder, J., Crooks, V.A., Adams, K., Kingsbury, P., Johnston, R., (2011) The "patient's physician 979 one-step removed': the evolving roles of medical tourism facilitators. Journal of Medical Ethics, 37, 9 , $980 \quad 530-4$

981 Sobo, E.J., Herlihy, E. and Bicker, M. (2011) Selling medical travel to US patient-consumers: the 982 cultural appeal of website marketing messages. Anthropology and Medicine, 18, 1, 119-36

983 Spence R.G. (2009) Medical Tourism: Protecting Patients from Conflicts of Interest in Broker's Fees 984 Paid by Foreign Providers. Arizona Legal Studies, Discussion Paper No. 09-41

985 Starr, P. (1982) The social transformation of American medicine. Basic Books.

986 Terzi, E., Kern, T. and Kohnen, T. (2008) Komplikationen nach refraktiver Chirurgie im Ausland.

987 Ophthalmologe, 105, 474-479

988 Timmermans, S. and Oh, H. (2010) The Continued Social Transformation of the Medical Profession.

989 Journal of Health and Social Behavior, 51S, 94-106

990 Tountas, Y., Karnaki, P., Pavi, E., Souliotis, K. (2005) The "unexpected" growth of the private health 991 sector in Greece. Health Policy, 74, 167-180

992 Turner, L. (2011) Quality in health care and globalization of health services: accreditation and 993 regulatory oversight of medical tourism companies. International Journal for Quality in Health Care, $994 \quad 23,1-7$

995 Turner, L. (2012) Canada's turbulent medical tourism industry. Canadian Family Physician, 58, 3719963

997 Turner, L. (2013) Transnational Medical Travel: Ethical Dimensions of Global Healthcare Cambridge 998 Quarterly of Healthcare Ethics, 22, 2, 170-180

999 Wachter, R.M. (2006) The "Dis-location" of U.S. Medicine - The Implications of Medical 1000 Outsourcing. The New England Journal of Medicine, 354, 661-665

1001 Wiersma, W. (1995) Research methods in education: An introduction (6th ed.). Boston: Allyn and 1002 Bacon.

1003 Woodhead, A. (2014) Scoping Medical Tourism and International Hospital Accreditation Growth, 1004 International Journal of Healthcare Quality Assurance, 27, 1 


\section{Acknowledgements}

1007 This research was funded by a $\mathrm{PhD}$ scholarship.

\footnotetext{
'The Philippinese company PMTI (http://www.philmedtourism.com) offers complete medical travel programmes. Medical doctors and/or members of their families are partners of the company (last retrieved 7/7/2011). Two out of five members of the directors' committee of the German Med2Heal are medical doctors and three out of four of the New Zealand's MEDTRAL (http://www.medtral.com) directors are MDs (last retrieved 7/7/2011). Furthermore, the president and CEO of the French facilitator 'My Treatment Abroad' (http://www.mymedicaltreatmentabroad.com/) is an MD himself (last retrieved 7/7/2011). CEO of the UK based portal The Medical Tourist Company (http://themedicaltouristcompany.com) is a medical doctor as well (last retrieved 7/7/2011).
} 